\title{
The Reform and the Future of Chinese Philosophy Education
}

\author{
Yu Xufeng \\ China Jiliang University \\ Hangzhou, China
}

\begin{abstract}
Looking back on the history of the reform of philosophy education in colleges and universities in recent years, people have carried out a lot of exploration work on the reform of the content of philosophy education in colleges and universities, like the innovation of philosophy and teaching methods, and the renewal of philosophy education concepts in colleges and universities, but it is necessary to further broaden their horizons and expand the field by conducting more in-depth research. This article is a research and exploratory article on the reform of philosophy education in higher normal colleges. We conducted in-depth research in colleges and universities, combined the reality of colleges and universities, discovered the malpractices and problems, tried to explore the educational purpose of Marxist philosophy, and proposed the philosophy education methods of colleges and universities. The innovative program of reform proposes new ideas and new insights for the majority of philosophers.
\end{abstract}

Keywords-Chinese philosophy education; university teaching system; reform and research

\section{INTRODUCTION}

Philosophy is the essence of knowledge in all ages and is the embodiment of human wisdom. In the long historical process, philosophers constantly think, strive to pursue the truth, and explore and expound the dialectical relationship between man and the world. Philosophy is indispensable. It deeply influences the progress and development of society. It is the embodiment of social civilization and a powerful driving force for human progress. The usefulness of philosophy is inevitable. From the perspective of cultivating people's moral sentiments and values, philosophy is indispensable and vital. Therefore, learning philosophy well and doing a good job in philosophy education have great practical significance for our country to cultivate and create socialist builders and successors. At the same time, Marxist philosophy is a materialistic philosophy. Contemporary college students armed with Marxist philosophy will become a new socialist builder and a new force representing the development direction of advanced productive forces. At the same time, philosophy education can also enhance our spiritual realm, expand our horizons and enhance our thinking ability. With the progress of our society and the development of civilization, social productivity has been greatly improved, and the material life and cultural accomplishment of the broad masses of the people have also made great progress, but there are still some residual feudal ideas and antiquated in society. The existence of ideas, they still ban some people's thinking. Only through the study of philosophy and the belief in Marxist philosophy can we help the people to break the superstition, update their ideas, and emancipate their minds.

\section{THE NECESSITY OF PHILOSOPHICAL EDUCATION IN CONTEMPORARY SOCIETY}

With the increasing complexity of social life and relationships, massive amounts of information are constantly coming to us. In this situation, philosophical thinking that is longer than holistic, general, abstract, reflective, and critical has increasingly highlighted its importance. In the vast ocean of information, it is the "metaphysical" way of thinking that can make the excessive complexity of things necessary to simplify, help us to surface, see directions, goals and ways. As a "view" of the world view, philosophy is not only a superficial phenomenon, but an insight into the inner essence, and thus a grasp of the overall, fundamental and regularity of the world. The "view" of philosophy can only be seen far because it stands tall. The concept of nature, history, life, society, culture, education, science, art, religion, values, etc. are all part of the philosophical concept. Although the "view" of various integrations cannot directly solve specific problems, it is the necessary integration in the process of dealing with specific problems. Without this kind of philosophical rationality, people will become trivial transaction lists who do not know the general and do not know the general trend. In the era of "fragmentation" caused by the so-called "information explosion", it is both a worldview and a philosophical reflection of methodology, and a theoretical way of thinking that consciously grasps the self and the world and their relationship rationally.

As the core content of the whole cultural education, philosophy education lies in inheritance and innovation. This essential relationship between inheritance and innovation runs through two major parts of philosophy education: professional education and general education. Relatively speaking, philosophy general education focuses on the cultural foundation and quality of philosophy, focusing on the inheritance of philosophical and cultural history; philosophy professional education focuses on the cultivation of the professional foundation and ability of philosophy, focusing on the future innovation of philosophy and culture. Of course, in the general education of philosophy, there is also the relationship between inheritance and innovation, as well as the ability to innovate on the basis of inheritance. Accepting a comprehensive philosophy of general education and cultivating innovative ability based on cultural heritage is conducive to creative activities in the philosophical or nonphilosophical field. When studying and dealing with the relationship between professional education and general 
education in philosophy, we need to have a clear sense of consciousness in line with objective reality: in-depth summarization of experience, discovery, problem-solving, analysis, judgment, and effective in understanding and practice. Solve the relationship between professional and general education. Discovering, analyzing, solving problems and promoting the development of philosophy education is innovation. Reform and innovation that conform to objective reality and solve real problems are effective ways to improve the quality of philosophy education and general education. Philosophy education is a humanistic education. The fundamental purpose is to cultivate people who are free and fully developed. The development trend of human beings determines the status quo and future of China's social development. China has entered a new era of innovationdriven development, and innovation has become the internal driving force for economic and social development. The transformation of China's social development from imitationdriven to innovation-driven has put forward higher requirements for Chinese education, including philosophy education: to cultivate talents with cultural innovation based on cultural heritage. At the same time, society also requires universities to become the base of cultural research and innovation, and to continuously provide new knowledge, new ideas, new theories and new methods in line with the future development needs of China and the world. China will become a strong independent innovation country in the next few decades, and university education, including philosophy education, shoulders a major historical responsibility. With a strong sense of historical responsibility, we should sum up the laws and methods of philosophy professional education and general education, and promote the innovation and integration of philosophy education and general education. University philosophy professional education and general education, like "Bird's wings, two wheels of the car", cannot be neglected. Dealing with the two-wing or two-round relationship of philosophy education will enable our philosophy education to develop healthily and rapidly, and play a greater role in the inheritance and innovation of Chinese culture and world culture.

\section{THE LAYOUT OF THE DEVELOPMENT OF PHILOSOPHY}

To truly prosper the cause of philosophy and education, we need a reasonable overall layout for the development of philosophy education. This general layout includes two parts: the scale of internal development of philosophy education and the scale of external development of philosophy education. The so-called internal scale of philosophy education refers to the distribution of undergraduate and graduate students in philosophy education in an "inverted triangle". That is to say, the scale of undergraduate education in philosophy education should be appropriately controlled, and the scale of the postgraduate stage can be appropriately expanded. This is determined by the attributes of philosophy itself. First of all, since philosophy is a metaphysical discipline, it does not have the social needs in the market sense. It is Marx's nonproductive spiritual production, which lacks the support of social dimension. Therefore, the development of philosophy education is not It may or should not have a large scale. Secondly, in recent years, the number of students who are the first volunteers to apply for the philosophy department is very small. In this case, it is difficult to maintain and expand the enrollment scale, and the non-volunteer candidates can learn the philosophy through adjustment and enrollment, which is contrary to the students' interest. Learning bad philosophy, on the other hand, because of the decline in the overall cultural quality of philosophy students, it further damages the reputation of philosophy education. Third, and more importantly, philosophy as a summary and generalization of knowledge in other disciplines, if there is no other academic background as a professional support point, purely from philosophy to philosophy, it is difficult to really go deep into philosophical research. In fact, for a long time, China's philosophical education does have shortcomings that lack the support of other disciplines, especially the natural science background. It is this excessive emphasis on the fine division of the profession, resulting in the lack of natural science literacy of philosophers, and the lack of philosophical literacy of natural science workers. The scale of external development of philosophy education means that in the universities and research institutes across the country, philosophy education is mainly based on comprehensive universities and research institutes with good academic foundations, forming a system with reasonable academic layout, and intensive philosophical education. the way. What we call developmental philosophy education is not the old way of returning to the extensive development of the so-called "philosophical prosperity period" in the past. At that time, almost all schools had a philosophy department to recruit undergraduate students in philosophy. However, philosophy is a metaphysical discipline. Only philosophical undergraduate education is not enough. At most, it can only undertake philosophical propaganda work, and truly in-depth research and dialogue with the international community requires a higher level of training. Therefore, in order to realize the prosperity of philosophy education, an important part of reforming philosophy education is to form a reasonable disciplinary arrangement on the basis of sufficient argumentation and consideration of regional differences, and to take the road of fine development of philosophy education. Another way to take the path of the development of philosophy education is to develop graduate education. In other words, the focus of philosophy education is on graduate education. First of all, with the deepening of the reform of colleges and universities, colleges and universities are paying more and more attention to humanities education, and the demand for graduates of philosophy majors continues to increase. Secondly, compared with undergraduate education, the number of graduate students who voluntarily apply for philosophical studies is on the rise, and it is all due to the willingness of candidates. Finally, because a large number of candidates who apply for postgraduate education in philosophy are out of interest and have an interdisciplinary knowledge background as a research support point, this has a good effect on the development of philosophy education itself. The future development direction of philosophy education is to deepen the reform and attract more and better students with other academic backgrounds and real interest in philosophy to enter the postgraduate training, so as to improve the quality of philosophy education in China as a whole. 
The internal reform of the philosophy curriculum system refers to the adjustment and reform of the philosophy system. In this respect, the curriculum system of the philosophy department of Fudan University has been relatively early and effective, so it has reference significance. They divided the undergraduate courses into compulsory courses and elective courses: compulsory courses include basic theory courses and theoretical history courses, which mainly cover the general knowledge courses of all the two disciplines of philosophy and the history of their thought development. Elective courses mainly include cross-disciplinary courses, skill courses and special courses. The former cultivates students with philosophical and general knowledge, while the latter provides students with a skill to go to society. In the master's and doctoral programs, in addition to the degree-based courses and degree elective courses, public compulsory courses in the secondary subjects of China, the West, and Malaysia are also set. Of course, the basic courses, degree electives, and public compulsory courses in the two stages of master's and doctoral degrees are different. For the basic course electives, the master's degree is centered on the original and the topic, while the doctoral students focus on the topic and frontier issues. For public compulsory courses, each student may be exempted from a public compulsory course in the second-level subject, but must take two other compulsory courses in the secondlevel subject. Taking the Marxist philosophy as an example, students in this subject can be exempted from the public compulsory courses of Marxist majors, but must take courses in Western philosophy and Chinese philosophy. The goal of this setting is to open up three secondary disciplines of China, the West and Malaysia, so that students have a broader vision and a more reasonable knowledge structure. The external reform of the philosophy education curriculum system includes two options. One is that the teachers of the philosophy department offer philosophy elective courses for undergraduates. On the one hand, they can improve the humanities quality of the students as a whole, and on the other hand, they can attract students interested in philosophy to pursue graduate studies across disciplines. One of the key points of the reform of philosophy education is to change the concept that philosophy teachers only engage in philosophy teaching in the philosophy department, and requires philosophy teachers to offer philosophy courses to all students.

\section{THE ORIENTATION OF THE TRAINING TARGET OF PHILOSOPHY TALENTS}

Philosophy education has three levels or stages like other disciplines: undergraduate, master, and doctoral students. Each stage has its own goals. For the undergraduate stage, it is necessary to consider that after graduation, there is a small number of people who choose to engage in philosophical research. Therefore, for this stage of philosophy education, students should mainly cultivate students' interest in learning philosophy and general knowledge of philosophy, and promote college students' Humanistic quality, with specific life skills and expertise. In other words, the undergraduate stage is not to train each student as a philosophical researcher, but to fully consider the dimension of social needs, and to position the goal of philosophy education in cultivating economic workers and management workers with better philosophical qualities. Socialist builders such as legal workers and journalists.

For the postgraduate stage, it is necessary to "train the students to become generalists in a second-level discipline of philosophy and to have a preliminary research ability". 2 From the perspective of pedagogy, this stage should cultivate students' philosophical learning ability. That is to say, through the training of the system at this stage, students can actively and enthusiastically contact a certain subject area of philosophy, familiar with the main literature in the field, master academic norms, possess the ability of cognitive philosophical problems, query and collect. The ability of relevant literature, the ability to read original work, the ability to interpret data, the ability to use knowledge, the ability to summarize results and the ability to publish conclusions. For the doctoral degree, it is mainly to train students to become a specialist in a research discipline in a second-level discipline of philosophy, and to have independent research and teaching capabilities. 3 The most important goal of this stage is the cultivation of the philosophical problem consciousness. The philosophical problem consciousness includes a very in-depth study of a certain research direction in a second-level discipline of philosophy, and can track the research dynamics and frontier issues at home and abroad in a timely manner, and can start from the problems raised by philosophy to the times. Carrying out philosophical thinking, thus having a high degree of philosophical thinking, philosophical judgment, philosophical criticism and philosophical sentiment.

Philosophy educators are first and foremost philosophical researchers. Directly related to the quality of teaching and the effect of teaching is the research of the professional research status of the educator and the theory of philosophy education. The so-called professional research means that the educators themselves have a relatively solid research foundation for the content they teach, and they can stand at the forefront of the field, and pass on their research results to students in a simple way, and improve the quality of teaching with professional research. Therefore, institutional arrangements should be used to promote the study of professions by philosopher educators. It must be pointed out that the current evaluation system should be reformed. The current evaluation mechanism not only does not motivate philosophical educators to engage in true philosophical research, but to some extent motivates people's impetuous and utilitarian short-term behavior. Don't say that this kind of evaluation mechanism can't produce masters, that is, to include a person who is already a master into the current mechanism, and his creativity will be killed. Because philosophical research as a special spiritual production is a highly creative activity. Real spiritual products cannot be copied in large quantities like industrial products. Feuerbach is also a distinction between industrial "manufacturing" and spiritual "production" in this sense, and emphasizes that "the true spiritual producer cannot produce continuously, just as the tree cannot continue to blossom and be strong." 4 Reasonable The incentive mechanism should respect the special laws of spiritual production in philosophical research.

In addition to professional research, educators should also engage in the study of philosophy education theory. Although 
the general educational theory has developed a lot and achieved many results, the philosophy of philosophy as a special subject has been weak and has not received much attention. Philosophy education does not form a systematic and complete theoretical system. Philosophy education is an applied education theory discipline. As an educational theory, it also includes four major parts: curriculum theory, textbook theory, teaching theory and teacher theory. As an applied theory, there are two meanings: First, philosophy education is at the junction of philosophy and education (especially teaching theory) and psychology. It combines these discipline theories and relies on them to solve their own problems. Form your own unique philosophy education theory. The second is that its theory comes from philosophy education and teaching practice, and it is reflected in the teaching of philosophy and teaching practice, and to test its theoretical value.

\section{THE ESSENCE OF THE REFORM AND INNOVATION OF PHILOSOPHY EDUCATION}

China's reform has a long way to go, and education reform needs to be deepened. The reforms in the past 40 years have achieved remarkable results. China has become a world education power, but it is not yet an education power. In the historical stage of comprehensively deepening reform, we need to seriously summarize and reflect on the status quo of philosophy education reform and clarify the direction of further reform. We should be clear about the idea that reform is not an end in itself and cannot be reformed for reform. Reform is the means of development. The prosperity and strength of the country, the progress of society, and the revival of the nation are the goals. No matter which field can be said, reform is focused on improvement, innovation is on excellence, and the value dimension of reform and innovation cannot be missed. The essence of the reform and innovation of philosophy education is to improve excellence and build a high-level philosophy education system with Chinese characteristics. Engels said well: "If a nation wants to stand at the highest peak of science, it can't be without theoretical thinking for a moment." History has proven that philosophy education is the most cultivated theoretical thinking. The important way. On the occasion of the Chinese national rejuvenation going to the forefront of the world, it is a wise move to attach great importance to and develop modern philosophy education, that is, theoretical thinking education.

Looking back at history, our philosophy education has experienced a tortuous path. At the beginning of reform and opening up, practice was a big discussion to test the sole standard of truth, and it continued to promote the development of philosophy education. Later, the narrow utilitarian orientation prevailing in the market economy greatly reduced the development space of philosophy education. Until the comprehensive, coordinated and sustainable scientific development concept and new development concept are established, philosophy education returns to its proper position and develops slowly and steadily. The question now is, from the overall situation and trend of China's economic, social and cultural development, what kind of prospects will there be in the coming decades? Will it show a gradual upward trend, or will there be a gradual decline? This is the first basic judgment we need to make when considering and planning the future development strategy of Chinese philosophy education. This issue should be studied as a major project topic. It needs to have historical, realistic and scientific basis. It cannot be judged solely by personal likes and dislikes. Based on our understanding of the history of philosophy education in various countries and nations of the world, based on the consideration of Chinese historical and cultural traditions and the development of contemporary economic, social and cultural trends, we tend to be cautiously optimistic. The fate of philosophical education is determined by the extent to which it meets the needs of society. The true needs of the state, society, and people for philosophy are undoubtedly the root of the existence and development of philosophy education. The development of social and human development from subsistence to well-being to a higher level is generally a process of upgrading from material needs to spiritual needs. In this sense, philosophy, as a core part of spiritual culture, obviously has a certain "post-development advantage."

China is modernizing, and the developed countries and regions in the world have surpassed industrialization and entered the post-industrial society, the information age. We are also striving to embark on the path of knowledge economy development. In the era of knowledge economy, science, technology, and information have become the primary productive forces, and philosophy seems to be dispensable. In fact, on the contrary, the social role of philosophy is becoming more and more prominent. There are only two reasons for this: First, in a society where the "information tide" is constantly coming, only a highly generalized and succinct philosophical way of thinking can make us like "the tide of the tide to the head." Second, the "knowledge economy" of the contemporary world is quietly transforming into a "smart economy", and the importance of philosophy, such as "wisdom of wisdom," is becoming more and more important. The importance of philosophy by the state, society, and the public is likely to become a new trend of thought. The demand for philosophy and philosophy education in the future world will show a steady upward trend. Our philosophy of professional education and general education (quality) education should improve quality through reform and innovation, and meet the needs of philosophical wisdom for the comprehensive development of society and people.

The development of education has its inherent regularity. The development of philosophy education must follow the laws of philosophy education. The history of the development of philosophy education has accumulated rich experience and lessons, showing some inevitability of this kind of education. We need to understand the regularity from the historical experience of philosophy education at home and abroad as a reference for our own philosophy education. Especially the path that modern philosophy education in western developed countries has gone through is worthy of our serious study and reference, because we are working hard to realize the modernization of education. We have gone through decades of philosophical education modernization for decades or even hundreds of years. There are different realistic conditions and development spaces for philosophical education at all levels in China. On the basis of comprehensively summarizing practical experience, in-depth exploration of the regularity of the 
development of contemporary Chinese philosophy education has become an inherent requirement for further improving the quality of education. Law is an intrinsic, stable, and inevitable connection in the development of things, and it is a trend that must be so in the development of things. Education is the way in which human culture inherits and develops. As mentioned above, the regularity in the development of education is concentrated in the relationship between inheritance and innovation. The general education and professional education in philosophy education promote each other and complement each other. Professional education should be based on general education, and general education should be led by professional education. Professional education that leaves general education and general education that leaves professional education are virtually impossible. In the philosophical education, the Bo and the specialization complement each other, and the two are beneficial to each other. The development of philosophy education in the combination of professional education and general education is in line with the law of philosophy education.

Our philosophy education must not only adapt to the needs of its own development, but also adapt to the needs of the country and social development. As a product and service provided by the cultural industry, philosophy education, with the needs of the state, society and the people for philosophy education, constitutes a relationship between supply and demand. What kind of demand will have what kind of supply, supply should adapt to the actual needs, and new and valuable supplies may also foster new and sustainable needs, so supply must also actively create and lead demand. In the contemporary era, we should study and grasp the general trend of philosophical theoretical thinking, thinking methods and related talent needs, so that the development of Chinese philosophical education can be adapted to the philosophical needs of the state, society and the people. It conforms to the "trend of the times", that is, it conforms to the regularity of development in the direction and overall. We need to grasp the structure, scale, goals, ways and methods of philosophy education in the dynamic development from the unity of discipline development law and social development law. In philosophy education, the relationship between knowledge and ability has a fundamental nature, and should be handled from the perspective of teaching or learning. The philosophical subject contains a large amount of knowledge and requires a certain degree of understanding or clarification. Learning the history of history and classic literature is the basic way to master the way of philosophical thinking. However, if the philosophical education is limited to the indoctrination of philosophical knowledge and the research of historical documents, it will weaken philosophy as the analysis, synthesis, generalization and expression of theoretical thinking. This is the difference between the two concepts of "common knowledge" and "quality". The "general knowledge" in people's minds often refers to general or common knowledge. In this sense, general education focuses on knowledge education; while "quality" is associated with ability. Quality education in this sense is obviously focused on ability education. . In view of the bias of knowledge and light ability in previous educational thoughts and practices, we should emphasize the ability education combined with knowledge education in the future philosophy education. For the so-called general education, it is necessary to focus on the understanding of competence education or quality education. The above-mentioned contradictory relationship between general education and professional education, subject supply and social needs, knowledge education and ability education touches on the regularity of contemporary philosophy education. The purpose of education is to cultivate talents. The law of education is to cultivate the rules of talents in an educational way. It is linked to the laws of human growth and development. The biggest obstacle in the development of education is to ignore the laws of human growth and development, resulting in a deformed one-sidedness rather than a free and comprehensive development. The problem of the law of education is internal and deep. The lack of consciousness on this issue and the blindness will cause serious damage to the development of society and people. In the ongoing education reform, we should seek the unification of the purpose and regularity of educational activities through continuous exploration and trial and error. Philosophy is the concentrated expression of human reason, and philosophy education should become the most conscious field of education. This kind of consciousness is the selfconsciousness of people's purpose for their own activities, and also the self-consciousness of the regularity of such activities. The rational human freedom is not to get rid of the inevitable willfulness, but to transform the real world with the premise of understanding the inevitability and following the law.

\section{UPDATE OF PHILOSOPHY TEACHING METHODS}

First, philosophy teaching should reflect the nature of philosophy. In fact, as early as in ancient Greece, Socrates created a unique method of philosophy for us, dialectics. The so-called dialectics is a question-and-answer logic that reveals reason through inter-subject dialogue, or that reason arises in dialogue. This gives us at least three aspects of enlightenment: First, the nature of philosophy is not a rational monologue, not a monopoly of discourse power, but a rational dialogue. The process of revealing the whole rationality is neither centered on the questioner nor on the side of the respondent, but exists between the interlocutors. This is very close to the communicative rationality advocated by Habermas today. Second, philosophy is a highly exploratory activity, always in an open dialogue, without a prior and fixed answer. Finally, philosophy is a kind of critical thinking. In the dialogue, constantly deconstructing the original fixed concept and constantly rebuilding the new concept is always a dynamic process. In this sense, philosophical teaching adopts heuristic teaching, discussion, debate, role playing and other methods more in line with the philosophical nature.

Second, Marxism believes that philosophy must not only explain the world, but also how to transform the world. In this sense, philosophy education should take social practice and social investigation as an important part of philosophy teaching, as required by the Ministry of Education Document No. 1.

Third, computer-assisted instruction and the Internet system can be used in philosophy teaching. One of the biggest advantages of computer-aided instructional systems is 
interactivity, so that teachers and students have a more equal voice and information is interactive. Conversational teaching is not limited to the classroom. The Internet provides a wider space outside the classroom. For example, the Internet can be used to establish a virtual philosophical research center or philosophical salon for students and teachers to express their opinions and exchange ideas.

\section{CONCLUSION}

The cultural function of university education lies in the inheritance and innovation of culture, and philosophy education is in a very important position. The inheritance and innovation of culture runs through two major parts of philosophy education: professional education and general education. Philosophy education is a humanistic education. The fundamental purpose is to cultivate people who are free and fully developed. We must not only be able to cultivate philosophical talents, but also be able to cultivate talents with philosophy. Developing philosophy education must follow the laws of philosophy education and improve the quality of philosophy education. Philosophy education is the most important way to cultivate theoretical thinking. On the occasion of the Chinese national rejuvenation going to the forefront of the world, it is a wise move to attach great importance to and develop modern philosophy education, that is, theoretical thinking education.

\section{REFERENCES}

[1] Sun Zhengqi. Several Issues on the Reform of Philosophy Education [J]. Philosophical Basic Theory Research, 2009:65-69.

[2] Han Zhen. Some Thoughts on the Reform of Philosophy Education [J]. Journal of Beijing Normal University: Social Science Edition, 2002(3): 113-117.

[3] Sun Zhengqi. Promoting the Reform of Philosophy Education and Improving the Philosophical Cultivation of the Chinese Nation [J]. University Teaching in China, 2006(6): 7-9.

[4] Pan Shimo, Yu Zhangbao. Reflections on the Reform of Philosophy Education in Colleges and Universities[J]. University Teaching in China 2003(7): 13-15.

[5] Gao Jingwen. Philosophical Meditation on Deepening Reform [J]. Journal of Xinjiang Education Institute, 1998(1):1-3.

[6] Ma Li. China's Higher Education and Its Reform[J]. Journal of Xinjiang University: Philosophy. Humanities and Social Sciences, 1992 (2): 1212.

[7] Chen Ni, Yuan Jianhui, Yuan Chenglin, et al. Discussion on the Reform of Innovation and Entrepreneurship Education in Universities Based on the Perspective of Philosophy [J]. Coastal Enterprises and Technology, 2016(4):74-76.

[8] Feng Heguo. Analysis of the Reform Path of School Education in China from the Perspective of Body Philosophy [J]. Modern Education Science: Higher Education Research, 2013(3): 34-36. 